WINCE ELMAN N-GESELLSCHATT STENDAL

JAHRESGABE $1956 / 57$ 

WINCKELMANN-GESELLSCHAFT STENDAL

JAHRESGABE 1956/57

\section{Johann Joachim Winckelmann}

Sprache und Kunstwerk

von

H A N A K OCH

Mit 8 Abbildungen

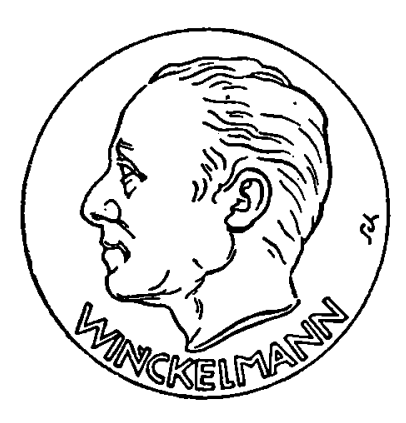

1957

AKADEMIE - VERLAG - BERLIN 
Copyright 1957 by Akademie:-Verlag GmbH, Berlin Alle Rechte vorbehalten

Erschienen im Akademie-Verlag GmbH, Berlin W 8, MohrenstraBe 39

Lizenz-Nr. $202-100 / 369 / 57$

Gesamtherstellung: IV/2/14 - VEB Werkdruck Gräfenhainichen - 719

Bestell- und Verlagsnummer: 5260

Printed in Germany 